EDUR • Educação em Revista. 2020; 36:e223925

DOI: http://dx.doi.org/10.1590/0102-4698223925

() (1) $\mathrm{https://creativecommons.org/licenses/by/4.0/}$

ARTIGO

\title{
HUGO DE SAINT-VICTOR: HISTÓRIA, MEMÓRIA E ORDENAÇÃO NOS ESTUDOS
}

\author{
ANA PAULA DOS SANTOS VIANA ${ }^{1}$ \\ ORCID: http://orcid.org/0000-0003-1523-8014 \\ TEREZINHA OLIVEIRA ${ }^{2}$ \\ ORCID: https://orcid.org/0000-0001-5349-1059
}

\begin{abstract}
RESUMO: Neste artigo, apresentam-se algumas reflexões sobre a sistematização do saber encontrada em duas obras do mestre medieval Hugo de Saint-Victor (1096-1141): Didascalicon, da arte de ler e De sacramentis christianae fidei. O objetivo principal do texto é mostrar como esse pensador atribuiu importância à história e à memória no ensino dos estudantes da Escola da Abadia de Saint-Victor, tendo em vista sua finalidade primordial: a sapiência. Quando se estuda a História da Educação, compreende-se que a reflexão sobre valores, independentemente de seu período histórico de elaboração, é pertinente à formação humana. Assim, entende-se que passado e presente estão relacionados e que, sem essa percepção, não é possível compreender as prioridades educacionais em distintos momentos históricos. Ao desprezar a memória e o conhecimento histórico, uma civilização caminha desnorteada, pois, quando não se conhece o passado, não se tem consciência do presente e não se tem perspectiva de futuro.
\end{abstract}

Palavras-chave: História da Educação Medieval, Memória, História, Sapiência, Hugo de Saint-Victor.

\section{HUGO DE SAINT-VICTOR (1096-1141): HISTORY, MEMORY AND ORDINATION IN THE STUDIES}

ABSTRACT: In this article, some reflections on the systematization of knowledge found in two works by the medieval master Hugo de Saint-Victor (1096-1141) are presented: Didascalicon, the art of reading and De sacramentis christianae fidei. The main objective of the text is to show how this thinker attached importance to history and memory in the teaching of students at the School of the Abbey of SaintVictor, in view of its primary purpose: wisdom. When studying the History of Education, it is understood that the reflection on values, regardless of their historical period of elaboration, is relevant to human formation. Thus, it is understood that past and present are related and that, without this perception, it is not possible to understand educational priorities at different historical moments. By

\footnotetext{
1 Professora da Rede de Ensino do município de Marialva-PR. Universidade Estadual de Maringá (UEM). Marialva, PR, Brasil.<ana_psviana@hotmail.com>

2 Professora Titular na Universidade Estadual de Maringá (UEM) junto ao Departamento de Fundamentos da Educação e ao Programa de Pós-Graduação em Educação. Maringá, PR, Brasil. < teleoliv@gmail.com> 
disregarding memory and historical knowledge, a civilization is bewildered, because when the past is not known, the present is not aware of and the future is not seen.

Keywords: History of Medieval Education, Memory, Story, Sapience, Hugo de Saint-Victor.

\section{HUGO DE SAINT-VICTOR (1096-1141): HISTORIA, MEMORIA Y ORDENACIÓN EN LOS ESTUDIOS}

RESUMEN: En este artículo, se presentan algunas reflexiones sobre la sistematización del conocimiento encontradas en dos obras del maestro medieval Hugo de Saint-Victor (1096-1141): Didascalicon, el arte de la lectura y De sacramentis christianae fidei. El objetivo principal del texto es mostrar cómo este pensador le dio importancia a la historia y la memoria en la enseñanza de los estudiantes en la Escuela de la Abadía de Saint-Victor, en vista de su propósito principal: la sabiduría. Al estudiar la Historia de la Educación, se entiende que la reflexión sobre los valores, independientemente de su período histórico de elaboración, es relevante para la formación humana. Por lo tanto, se entiende que el pasado y el presente están relacionados y que, sin esta percepción, no es posible comprender las prioridades educativas en diferentes momentos históricos. Al ignorar la memoria y el conocimiento histórico, una civilización se desconcierta, porque cuando no se conoce el pasado, el presente no se da cuenta y el futuro no se ve.

Palabras clave: Historia de la Educación Medieval, La memoria, Historia, La sabiduría, Hugo de SaintVictor. 


\section{INTRODUÇÃO}

Hugo de Saint-Victor (1096-1141), um mestre da Escola da Abadia de Saint-Victor em Paris, deixou uma vasta obra, da qual "cerca de 250 títulos chegaram aos dias atuais" (GRYZBOWSKI, 2014, p. 129). Esse pensador teve papel fundamental na História da Educação Medieval, campo sobre o qual concentramos nossas pesquisas e reflexões.

Neste texto, pretendemos examinar as obras Didascalicon, da arte de ler e De sacramentis christianae fidei, consideradas as mais proeminentes pelos estudiosos do período, como Sicard (1991), Marchionni (2001) e Verger (2001). Aas duas estão reunidas em três volumes (Tomus 175, 176, 177) da Patrologia Latina de Jacques Paul Migne (1880).

Utilizamos a tradução ${ }^{3}$ de Didascalicon realizada por Antonio Marchionni e publicada em edição bilíngue pela editora Vozes. Destinada, primeiramente, aos estudantes da escola da Abadia de Saint-Victor, essa obra contém seis livros: três destinados ao conhecimento das coisas do homem pela leitura dos escritos literários e três, ao conhecimento das coisas de Deus pela leitura da Sagrada Escritura. Essa equidade na divisão da obra entre o âmbito da razão e o da fé revela a unidade corpoespírito, material-imaterial, teoria-prática, temporal-eterno, pensamento-ação, manual-intelectual na perspectiva de Hugo de Saint-Victor. Alguns estudiosos (MARCHIONNI, 2001; VERGER, 2001) identificam-na como um currículo medieval de estudos, pois apresenta aos estudantes uma sistematização do saber, entendido como a tradição do conhecimento, e um método de ensino pertinente à apropriação dos conteúdos: a filosofia composta pelas ciências dispostas em quatro esferas (teórica, prática, mecânica e lógica), nas quais se situam as artes liberais do trivium (gramática, retórica e dialética) e do quadrivium (aritmética, geometria, música e astronomia).

Da obra De sacramentis ${ }^{4}$ utilizamos a versão latina organizada por Jacques Paul Migne (1880). Considerada a summa teológica de Hugo de Saint-Victor (MARCHIONNI, 2001; VERGER, 2001; GRYZBOWSKI, 2014), De sacramentis é "[...] uma sistematização da totalidade dos elementos do mistério da fé cristã, como se concebia no início do século XII” (GRYZBOWSKI, 2014, p. 129). Nesse tratado, o mestre vitorino centra suas reflexões em "[...] como o homem pode ser restaurado [...]" (HUGONIS DE S. VICTORE, 1880, p. 264, tradução nossa), compilando ideias sobre a redenção do gênero humano e discorrendo sobre duas concepções: a conditio e a restauratio. Segundo Poirel (1997), De sacramentis foi escrita provavelmente entre $1136-1141^{6} \mathrm{em}$ dois livros (volumes) e seus respectivos prólogos.

O primeiro livro é composto por doze partes, ou 283 capítulos, nos quais o autor abordou desde o princípio do mundo até a narrativa da condução da encarnação do Verbo. O segundo é composto por dezoito partes, que, em sua totalidade, perfazem 225 capítulos, nos quais ele tratou desde a encarnação do Verbo até o estado futuro das gerações.

Ao buscarmos o entendimento histórico das obras de Hugo de Saint-Victor, encontramos as palavras de Verger (2001) sobre a reforma da Igreja, as quais elucidam as formulações do mestre vitorino. Como o autor explica, esse movimento histórico

\footnotetext{
${ }^{3}$ Essa tradução foi realizada por Marchionni (2001) a partir do texto latino da edição crítica de Charles Henry Buttimer, publicada nos Estados Unidos em 1939 a partir da Patrologia Latina de Migne (1879): HUGONIS DE SANCTO VICTORE, Didascalicon De Studio Legendi, a critical text by Brother Charles Buttimer, M.A., Washington, The Catholic University Press,

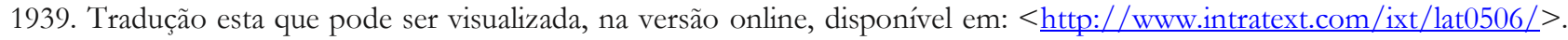
Acesso em 03 set. 2018.

${ }^{4}$ Cumpre esclarecer que, no decorrer da pesquisa, procurando compreender as formulações do mestre vitorino, realizamos um trabalho de tradução do textos em latim para a língua portuguesa, podendo assim corroborar os raciocínios desenvolvidos aos longo do texto com citações em português.

5 “[...] qualiter sit reparatus homo [...]” (HUGONIS DE S. VICTORE, De sacramentis..., L. I, p. VI, c. 1).

${ }^{6}$ Em relação à data, a bibliografia consultada não apresenta um consenso sobre a composição dessa obra. Contudo, Poirel (1997) conclui, após um estudo comparativo, que o tratado [De sacramentis] deve ter sido finalizado antes de surgir o conflito entre Abelardo e Bernardo de Claraval: no inverno de 1138-1139. Segundo Poirel (1997), Verger (2001)e Sicard (1991), essa obra da maturidade intelectual é o mais célebre dos escritos do mestre vitorino. 
[...] foi inicialmente reforma do clero secular e revalorização de seu papel (predição e sacramentos), ao menos ao nível dos bispos e dos cônegos, das paróquias [...] Isto exigia maior número de clérigos cultos, logo, formadores nas escolas. Isto implicava em um esforço intelectual sistemático de formatação [...] Campos consideráveis se abriram assim à reflexão e à ação dos clérigos instruídos (VERGER, 2001, p. 26-27).

Ao afirmar que essa reforma exigia um número expressivo de clérigos cultos, formadores nas escolas e que propunha a valorização do papel do clero, ressaltando a predição e os sacramentos, Verger (2001) chama nossa atenção porque encontramos esses aspectos nas obras de Hugo de SaintVictor. Em De sacramentis, na Nona Parte do Primeiro Livro, ele dedica oito capítulos aos sacramentos: o que eles são, por que foram instituídos, a quem pertencem, entre outras questões a eles relativas.

Entendemos que os aspectos históricos mencionados por Verger (2001), sobretudo a Reforma, foram possíveis motivações para que o mestre vitorino redigisse tal obra. Primeiramente, inferimos que o contexto histórico ${ }^{7} \mathrm{em}$ que Hugo de Saint-Victor viveu e, por conseguinte, desempenhou seu ofício na docência e na organização da Escola de Saint-Victor em Paris é um "[...] tema fundamental da política da civilização cristã ocidental - a Reforma Papal” (COELHO, 2013, p. 15).

O contexto era eminentemente favorável [...] era o contexto de uma Paris em pleno desenvolvimento em que as escolas se multiplicavam, particularmente na Rive Gauche onde se situava Saint-Victor. A própria abadia, protegida pelo rei, estava em pleno crescimento e se impôs, precisamente na época de Hugo, tanto como um dos principais centros da reforma canonical, quanto como um foco importante da vida intelectual (VERGER, 2001, p. 78).

A Abadia, ou Escola de Saint-Victor, floresceu como um centro intelectual e, conforme as palavras de Verger, tornou-se uma importante instituição no rol das escolas urbanas desse período, contribuindo não somente para o fortalecimento do clero e do reinado, mas também para o desenvolvimento da sociedade.

Pressupomos que, para se destinar ao ensino, as duas obras de Hugo de Saint-Victor (10961141) precisavam conter uma sistematização do saber. Propondo-nos a entendê-la, fomos instigados a fazer alguns questionamentos: o que era e para que servia essa sistematização? Por que os estudantes do século XII, particularmente os da Escola de Saint-Victor, precisavam sistematizar o saber?

A resposta que Hugo de Saint-Victor daria a esses questionamentos parece-nos clara. A arte, a teologia, o direito, a medicina teriam a finalidade de conhecer as dádivas da natureza e, assim, conhecer o Artífice dela. Ler e ensinar eram considerados um caminho para a sapiência, porque esta possibilitaria chegar à transformação ou, na concepção vitorina, à restauração humana.

Como todas as artes são subservientes à sabedoria divina

$\mathrm{E}$, assim, é evidente que todas as artes naturais servem à ciência divina e que a sabedoria inferior, corretamente ordenada, leva à superior. Assim, esse é o significado das palavras em relação às coisas que a história contém que, como se disse, é servida por três ciências, isto é, a gramática, a dialética e a retórica. É nesse sentido, contudo, que consiste o significado das coisas em relação aos fatos místicos, que a alegoria está contida. É nesse sentido, que consiste no significado das coisas em relação às coisas místicas a serem feitas, que a tropologia está contida, e estas duas são servidas pela aritmética, pela música, pela geometria, pela astronomia e pela física. Além desses, há, acima de tudo, aquela ciência divina à qual a Escritura divina conduz, seja na alegoria ou na tropologia; a que está na alegoria, forma (ensina) a fé correta, a outra, que está na tropologia, ensina o bom trabalho. Nestes consistem o conhecimento da

\footnotetext{
${ }^{7}$ Hugo de Saint-Victor viveu em uma época de expressivas alterações no cenário político, religioso, econômico, social, intelectual e cultural do medievo ocidental. Assim, conviveu com a expansão da Europa por meio das cruzadas, com a crise de suas instituições na disputa entre sacerdotium e regnum pelo poder das investiduras, com as reformas internas da instituição eclesiástica por meio do programa gregoriano e dos movimentos de reforma monástica de Cîteaux e seus contemporâneos; com o florescimento dos centros intelectuais da Europa (VERGER, 2001; LE GOFF, 2007; GRYZBOWSKI, 2014). 
verdade e o amor da virtude: e esta é a verdadeira restauração do homem ${ }^{8}$ (HUGONIS DE S. VICTORE, De sacramentis..., 1880, p. 185, grifo nosso, tradução nossa).

O mestre vitorino defendia uma formação humana e intelectiva baseada na união de saberes laicos (artes liberais) e saberes sagrados (ciência sagrada). Nessa unidade formativa está expresso seu entendimento de educação, já que o fim de sua proposta educativa seria a unidade restaurativa do homem. A sistematização do saber seria permeada pelo conhecimento das artes naturais que servem à ciência divina, pois ele entendia que a sabedoria é vivenciada na vida inferior e, quando ordenada, conduz à sabedoria superior. Desse modo, ao desenvolver o pensamento/a razão pelo crivo sapiente das reflexões das ciências sagradas, o homem teria a possibilidade de se aproximar da sapiência, do Artífice da criação. Ou seja, teria vivenciado o conhecimento da verdade e o amor à virtude e, com a vivência dessa gama de conhecimento, seria coroada sua real restauração. Por isso, para Hugo de SaintVictor, a memória estaria interligada à inteligência, pois o estudante que não fosse capaz de recordar o que havia estudado, de fato, não aprendera, ou seja, não teria assimilado a sistematização do saber.

Vejamos quais são os requisitos para que o homem chegasse a esse conhecimento, na perspectiva vitorina.

\section{ORDENAÇÃO NO ESTUDO}

Hugo de Saint-Victor indica cinco fases nos estudos para se atingir o conhecimento: 1) leitura ou instrução, 2) meditação, 3) oração, 4) prática, 5) contemplação. A primeira levaria ao entendimento; a segunda, ao discernimento; a terceira, à súplica, ou seja, à elevação do pensamento para a profícua reflexão; a quarta, à procura; e a quinta, ao resultado desse empenho. Para que os cinco estágios fossem realizados, o mestre vitorino recomendava um caminho: 'o modo de ler consiste em dividir'.

Toda divisão começa das coisas finitas e progride até as infinitas. Tudo aquilo que é finito é mais conhecido e mais compreensível pela ciência. A aprendizagem começa das coisas que são mais notas e, pelo conhecimento delas, chega ao conhecimento das coisas ocultas (HUGO DE SAINT-VICTOR, 2001, p. 149).

Para buscar a totalidade do saber (Deus), segundo ele, seria preciso delinear um caminho metodológico e, no caso, condizente com o aprendiz. Afirmava que o aprendizado principia pelas coisas singulares (mais conhecidas, 'notas', 'finitas') para então chegar às mais abrangentes, mais complexas ('ocultas', 'infinitas'). Assim, considerando a relação entre escrito e leitura, o método e a ordenação seriam requisitos essenciais para o estudo. Hugo de Saint-Victor enfatizava as regras necessárias ao ato de ler: "São três as regras mais necessárias para a leitura: primeiro, saber o que se deve ler; segundo, em que ordem se deve ler, ou seja, o que ler antes, o que depois; terceiro, como se deve ler". (HUGO DE SAINT-VICTOR, 2001, p. 45, grifo do autor).

Além da ordenação nos estudos seria preciso ter disciplina, humildade, dedicar-se à meditação, à memória, à pesquisa e, também, ao silêncio, à quietude necessária na vida. Assim, por meio de "[...] estudos honestos e úteis" (HUGO DE SAINT-VICTOR, 2001, p. 165), o homem

${ }^{8}$ CAP. VI. Quomodo omnes artes subserviunt divinae sapientiae.

Ex quo constat quod omnes artes naturales divinae scientiae famulantur; et inferior sapientia recte ordinata ad superiorem conducit. Sub eo igitur sensu qui est in significatione vocum ad res, continetur historia; cui famulantur tres scientiae sicut dictum est, id est grammatical, dialectica, rhetorica. Sub eo autem sensu qui est in significatione rerum ad facta mystica, continetur allegoria. Et sub eo sensu qui est in significatione rerum ad facienda mystica, continetur tropologia, et his duobus famulantur arithmetica, musica, geometria, astronomia et physica. Super haec ante omnia divinum illud est ad quod ducit divina Scriptura sive in allegoria, sive in tropologia: quorum alterum (quod in allegoria est) rectam fidem, alterum (quod in tropologia est) informat bonam operationem: in quibus constat cognitio veritatis et amor virtutis: et haec est vera reparatio hominis (HUGONIS DE S. VICTORE, De sacramentis..., Prologus, c. 6, grifo nosso). 
alcançaria, dentre outras coisas, o discernimento e o despojamento de coisas supérfluas. Além dos princípios pedagógicos, Hugo de Saint-Victor propunha um caminho teórico, mapeado pela mística ${ }^{9}$ e pela Trindade. Cada um desses princípios era intrínseco aos demais, pois todos compunham uma unidade: o projeto educativo do mestre vitorino.

Três coisas são necessárias aos estudantes: 1) as qualidades naturais, 2) o exercício e 3) a disciplina. As qualidades naturais, para que entenda facilmente aquilo que ouve e memorize firmemente aquilo que entendeu. $\mathrm{O}$ exercício, para que eduque as qualidades naturais mediante o trabalho e a persistência. A disciplina, para que, vivendo em modo louvável, harmonize a conduta com o saber (HUGO DE SAINT-VICTOR, 2001, p. 147).

Analisaremos a seguir cada um dos aspectos necessários ao estudo, destacando que, em diversas partes da obra, aparece o tríplice entendimento didático do mestre vitorino. Esse entendimento revela que seu caminho metodológico era mapeado pela Trindade.

Em relação ao primeiro aspecto necessário ao estudo, o mestre vitorino assevera que, para obter conhecimento, é importante que a pessoa disponha de inteligência e memória ao mesmo tempo: “[...] coisas que em qualquer estudo ou disciplina estão tão conexas que, se uma faltar, a outra não pode conduzir ninguém à perfeição, da mesma forma que os lucros servem para nada se faltar o armazenamento [...]" (HUGO DE SAINT-VICTOR, 2001, p. 147); ninguém construirá um armazém (comércio) se não tiver nada para guardar (se não se reverter em rendimento). Segundo ele, "O engenho descobre e a memória custodia a Sabedoria" (HUGO DE SAINT-VICTOR, 2001, p. 147), ou seja, o estudo permite o desenvolvimento intelectivo (o engenho) e, ao desenvolvê-lo, o homem aprimora e abstrai o conhecimento, adquirindo, por meio da memória, a sabedoria.

Sobre a memória, considero agora que não pode ser esquecido isto: como o engenho investiga e descobre, dividindo, assim, a memória guarda, resumindo.

Forçosamente, portanto, aquilo que dividimos aprendendo, devemos sintetizá-lo para ser confiado à memória. Resumir significa reduzir aquilo que qual foi falado ou escrito prolixamente para uma compilação breve e compendiosa que os antigos chamavam de epílogo, isto é, uma breve recapitulação das coisas ditas antes. De fato, qualquer tratado possui algum conceito basilar, sobre o qual toda a verdade da coisa e a força da argumentação se baseiam, e a ele todas as outras coisas se referem. Procurar e centrar isto é resumir.

Há uma fonte e muitos riachos: por que você segue as tortuosidades do rio? Fique com a fonte, e tem tudo. Afirmo que a memória do homem é fraca e gosta da brevidade, e se ela se dissipa em muitas coisas, fica menor em cada uma delas. Devemos, portanto, redigir em cada doutrina algo breve e certo, a ser depositado no arquivo da memória, do qual, em seguida, quando for necessário, as outras coisas derivem. Este resumo deve também ser revisitado freqüentemente e, do ventre da memória, ser chamado de volta para o paladar, para que não desapareça em virtude de um longo abandono.

Por isso, aconselho a você, estudante, a não alegrar-se excessivamente por ler muitas coisas, mas por entender muitas coisas, e não somente entender mas poder memorizar. Do contrário, não adianta ler muito nem entender muito. Razão pela qual repito quanto disse acima, isto é, que as pessoas que se dedicam ao estudo necessitam de engenho e de memória (HUGO DE SAINT-VICTOR, 2001, p. 153).

A memória é condição de aprendizado para Hugo de Saint-Victor. Como um dos vetores da Escolástica, ela possibilita à pessoa preservar o conhecimento. Não basta apenas a leitura de diversos escritos, mas, por meio da memória, é possível a apreensão dos conteúdos de cada um deles, ou seja, a memória guarda o que se aprende com a educação - com as artes liberais. Para tanto, é preciso o engenho, que seria o desenvolvimento do intelecto.

O segundo aspecto é o exercício desse engenho, o que, segundo Hugo de Saint-Victor (2001, p. 147), “[...] se dá mediante duas atividades: a leitura e a meditação. Na leitura, a partir de quanto

${ }^{9} \mathrm{O}$ encontro da alma (anima - princípio animador do corpo) com Deus.

Educação em Revista|Belo Horizonte|v.36|e223925|2020 
foi escrito, ficamos formados nas regras e nos preceitos [...] Na leitura devem ser tidos em máxima consideração a ordem e o método". Além da ordenação já exposta anteriormente (o que, como e por que ler), Hugo de Saint-Victor oferece uma exemplificação: a leitura de um texto consiste em primeiro inquirir a frase, depois o sentido, para então contemplar o pensamento, disso resultará um claro entendimento.

A meditação, por seu turno, "[...] é um pensar freqüente [sic] com discernimento, e investiga prudentemente a causa e a origem, o gênero e a utilidade de cada coisa" (HUGO DE SAINTVICTOR, 2001, p. 151). Significa dispor-se a pensar com expressiva concentração de espírito no exercício da leitura, refletir sobre a conduta humana, prezando o conhecimento minucioso dos ensinamentos sagrados e seculares.

O terceiro aspecto é a disciplina para o estudo: a harmonia entre a conduta e o saber, ou seja, a forma como os homens pensam, agem e vivem em consonância com o conhecimento ético ${ }^{10}$. Dessa perspectiva, o início da disciplina reside na humildade, sobre a qual existem muitos ensinamentos e o mestre vitorino destaca três deles: não desvalorizar a ciência e o escrito; não se envergonhar de aprender, independentemente de com quem seja e não desprezar os sujeitos depois de ter alcançado o saber (HUGO DE SAINT-VICTOR, 2001).

O bom estudioso deve ser humilde e manso, afastado totalmente das preocupações vãs e ilícitas de volúpias, diligente e constante, para que aprenda com prazer de todos, nunca presuma de sua ciência, fuja dos autores de doutrinas perversas como do veneno, aprenda a refletir longamente sobre alguma coisa antes de julgá-la, não queira ser douto, mas sê-lo, ame os ensinamentos aprendidos dos sábios e procure tê-los sempre diante dos olhos como espelho do seu próprio rosto. E se, por acaso, certas coisas mais obscuras não são admitidas por sua inteligência, o bom estudioso não prorrompa em impropérios, como se cresse que nada é bom a não ser aquilo que ele pode entender. Esta é a humildade da disciplina dos estudantes (HUGO DE SAINT-VICTOR, 2001, p. 159).

A humildade e a mansidão preservam o estudante para que leia e escute, com atenção, todos os escritos e, com isso, absorva os bons ensinamentos que cada um desses possa lhe oferecer. A reflexão, por sua vez, é consequência desses requisitos; afinal, como afirma o mestre vitorino, devemos aprender a refletir minuciosamente sobre todo escrito (conhecimento), pois, desta forma, não faremos julgamentos ou, ao menos, teremos ciência do que é tratado/estudado sem menosprezar o que o outro tem a transmitir.

O mestre assinala que o bom estudioso não se refere de forma impetuosa e ofensiva ao que desconhece ou age de forma repreensiva, julgando que apenas seu conhecimento é o melhor e que o ensinamento que ainda não entendeu é desnecessário, ou seja, precisa estar aberto ao conhecimento e ouvir com atenção. É preciso dedicação para meditar e memorizar os ensinamentos, para que isso faça parte de suas ações e da pesquisa:

A dedicação à pesquisa pertence ao campo do exercício, e nisto o estudante precisa mais de exortação que de ensinamento. Aquele que quisesse olhar diligentemente o que os antigos suportaram pelo amor da Sabedoria e quantas memórias memoráveis de sua virtude deixaram aos pósteros, verá quanto à sua diligência é inferior à deles. Uns calcavam as honras, outros jogaram no ar as riquezas, uns se alegravam com as injúrias recebidas, outros desprezavam os sofrimentos, outros, deixando o convívio dos homens e adentrando-se nos últimos recantos nas solidões do ermo, se dedicavam somente à filosofia, para entregar-se à meditação tanto mais livremente quanto menos submetessem o espírito às volúpias que costumam impedir o caminho da virtude. Conta-se que o filósofo Parmênides passou quinze anos num rochedo do

10 "O inventor da ética foi Sócrates, que sobre ela escreveu vinte e quatro livros acerca da justiça positiva. Em seguida Platão, discípulo dele, compilou vários livros Sobre a república a respeito das duas justiças, a natural e a positiva. Mais tarde Cícero organizou os livros Sobre a república em língua latina" (HUGO DE SAINT-VICTOR, 2001, p. 133). O conhecimento ético para o mestre vitorino, que se pautava nos filósofos mencionados, implica a possibilidade de convivência e de ação social entre os homens, a manutenção ou a preservação de uma harmonia, uma ordem social.

Educação em Revista|Belo Horizonte|v.36|e223925|2020 
Egito. E Prometeu é recordado exposto ao abutre no monte Cáucaso por causa da vontade desmedida de meditar. Estes eremitas, sabendo que o verdadeiro bem não reside na estima dos homens, mas está escondido na consciência pura e que não são homens quantos, aderindo às coisas que perecem, desconhecem o seu próprio bem, demonstravam com a distância geográfica quanto diferiam dos outros na mente e na inteligência, não querendo que uma mesma habitação albergasse aqueles que não eram associados na mesma intenção. (HUGO DE SAINT-VICTOR, 2001, p. 161).

Com Hugo de Saint-Victor, compreendemos que o empenho no estudo, na pesquisa, faz parte da vida do estudante. Não há ruptura entre o ser e o que ele estuda, conhece. Esse labor, no entanto, nem sempre vem acompanhado de louvor, de reconhecimento: pelo contrário, o mestre vitorino oferece alguns exemplos de pensadores que vivenciaram as adversidades dessa dedicação, denotando a consciência e a pertinência de sua existência em âmbito social. Aquilo que somos (os pensamentos e as ações humanas) respinga no bem comum porque somos parte constituinte de uma sociedade.

A quietude da vida é pertinente ao estudo: “[...] seja interior, para que a mente não se perca em desejos ilícitos, seja exterior, para que o ócio e a comodidade permitam estudos honestos e úteis, ambas pertencem à disciplina moral” (HUGO DE SAINT-VICTOR, 2001, p. 165).

Analisemos dois aspectos da quietude referida por Hugo de Saint-Victor: o silêncio e o ócio. Pôr-se em silêncio pressupõe fundamentar-se misticamente, encontrar uma paz interior que potencialize o desvencilhar-se dos desejos concupiscentes, pois, assim, será possível se dedicar com mais equilíbrio ao ato da aprendizagem. Em consonância com esse equilíbrio está o ócio, cuja conotação é diferente da dos dias de hoje, ou seja, seu sentido não é de inatividade, preguiça, indolência. Para o autor, otium (ócio) significa repouso, tempo livre, dedicação ao saber, que principia pela leitura e chega à meditação e à contemplação. Ele entende como quietude da vida ter tempo livre para a dedicação ao estudo e conduzi-lo com ordenação e método. Caso contrário, o ócio seria motivo de vergonha para o estudante, demonstraria que este estaria desperdiçando a preciosidade do tempo em coisas supérfluas, inúteis.

\footnotetext{
Deve-se saber que em qualquer trabalho são necessárias duas coisas: a aplicação e o método da aplicação, e estas duas coisas são tão conexas entre si, que uma sem a outra é ou inútil ou pouco eficiente. Com efeito, se diz que "a prudência é melhor que a força", porque às vezes levantamos com a habilidade os pesos que não podemos mover com as forças físicas. $O$ mesmo se dá em qualquer estudo. Aquele que trabalha sem método, trabalha muito, sim, mas não avança e, como a chicotear o ar, espalha as forças ao vento. Repare em duas pessoas atravessando o bosque, uma suando através de desvios, a outra escolhendo os atalhos de um traçado reto: fazem o percurso com o mesmo ritmo, mas não chegam no mesmo tempo. E o que denominaria eu a Escritura senão uma floresta, cujas frases colhemos na leitura como se fossem frutos dulcíssimos e as ruminamos na reflexão? Aquele, portanto, que em tão grande multidão de livros não mantém um método e uma ordem de leitura, este, como se vagueasse na densidade da floresta, perde o caminho do percurso certo "sempre estudando - como se diz - nunca chegando ao saber” (HUGO DE SAINT-VICTOR, 2001, p. 217).
}

Entendemos que a finalidade atribuída pelo mestre vitorino à sistematização do saber era edificar a formação dos estudantes, para que tivessem uma fundamentação teórico-prática que lhes permitisse obter essa solidez, essa consistência.

A seguir, mostraremos que, para o autor, o conhecimento da história era fundamental: [...] toda edificação sem fundamento não pode ser estável, o mesmo se dá no estudo. E o fundamento e o princípio da ciência sagrada é a história, da qual deriva a verdade da alegoria, como o mel do favo. (HUGO DE SAINT-VICTOR, 2001, p. 241). 


\section{A HISTÓRIA: PRINCÍPIO E FUNDAMENTO DA EDUCAÇÃO VITORINA}

Inicialmente, iremos abordar a maneira como o autor pensa, compreende e descreve a história em suas obras e como ele vivenciou o processo histórico contexto do século XII. Sua exposição é metódica, didática, expressa sua função de mestre e, por conseguinte, suas orientações no processo de formação de seus estudantes e da organização da escola.

Hugo de Saint-Victor começa seu discurso com os ensinamentos do local e do ofício em que esteve inserido. "Sem dúvida é mister no estudo que você aprenda, antes de tudo, a história e a verdade dos fatos, retomando do começo ao fim 1) o que foi feito, 2) quando foi feito, 3) onde foi feito, 4) por quais pessoas foi feito" (HUGO DE SAINT-VICTOR, 2001, p. 235). Assim entendida, a história é, ao mesmo tempo, o fundamento e o princípio para que os estudantes solidifiquem seus estudos. Observamos, então, que a ciência sagrada e, por conseguinte, as Sagradas Escrituras entrelaçam a educação vitorina. Esta conferiria unidade porque ele considera o processo histórico como base da ciência sagrada.

O autor compara a leitura das Escrituras com a construção de um edifício: a base é a história, as paredes, a alegoria, e o telhado, a coroa de toda a tropologia. Com esse exemplo, ele explica a importância de uma formação consistente, o que é intrínseco à sua compreensão a respeito da pertinência da história:

Dispondo-se a edificar, portanto, 'primeiro ponha o fundamento da história, depois, por meio da significação simbólica, erga o edifício da mente como fortaleza da fé. Por fim, por meio da beleza da moralidade, pinte o edifício com uma belíssima mão de cor' (HUGO DE SAINTVICTOR, 2001, p. 241).

Observamos que a disposição dessa edificação contém três instâncias, amalgamadas entre si: a da Escritura Sagrada, a da história e a do princípio educativo.

A primeira instância nos estudos seria o tríplice entendimento da Sagrada Escritura: “[...] a Sagrada Escritura apresenta três modos de entendê-la, a saber, 1) o modo histórico, 2)o modo alegórico, 3) o modo tropológico (morah)" (HUGO DE SAINT-VICTOR, 2001, p. 205).

Ao descrever o modo histórico, Hugo de Saint-Victor (2001, p. 230, grifo do autor) explica que precisaríamos usar "[...] um significado mais amplo desta palavra, isto é, se chamarmos história não apenas a narração dos fatos, mas aquele primeiro significado de qualquer narração que se expressa pela propriedade das palavras, nenhum livro é impróprio". Com essa acepção, o mestre adverte que o sentido e o significado contido nas Escrituras Sagradas não é apenas o da narração dos fatos, mas também o que nelas pode ser ensinado e aprendido por meio do entendimento histórico, salvaguardando juízos de valor: "[...] é necessário examiná-las com grande discernimento, se não queremos, por negligência, preterir algo, ou, por um zelo inoportuno, torcê-las violentamente para um sentido para o qual não foram escritas" (HUGO DE SAINT-VICTOR, 2001, p. 241).

Chenu (1999), na obra La Teologia nel XII secolo, tratando da consciência histórica e teológica no período em tela, corrobora a concepção de história de Hugo de Saint-Victor e seu tríplice entendimento da Sagrada Escritura. Segundo ele, a "bistória designa o conteúdo, e a partir desse conteúdo, a forma de pensar uma economia religiosa" "11 (CHENU, 1999, p. 74, tradução nossa, grifo do autor). A economia religiosa que Chenu identifica no pensamento vitorino é relacionada ao conceito de economia na Teologia. Nesse caso, tal conceito designa a ação de Deus na história. Em sua concepção de história, Hugo de Saint-Victor não desconsidera a pertinência de se ler os autores seculares (profanos). Entende o autor que as pessoas deveriam ler o máximo possível de escritos para, assim, saber distinguir o que lhes proporciona humanidade e conhecimento e o que não lhes

\footnotetext{
11 "bistoria designa il contenuto, e, a partire da questo contenuto, il modo di pensare, di un'economia religiosa" (CHENU, 1999, p. 74).
} 
proporciona sabedoria. Neste caso, a leitura seria pertinente para conhecer por experiência, adquirir capacidade de discernimento e, assim, chegar a um pensamento reflexivo.

O estudante prudente, portanto, ouve todos com prazer, lê tudo, não despreza escrito algum, pessoa alguma, doutrina alguma. Pede indiferentemente de todos aquilo que vê estar-lhe faltando, nem leva em conta quanto sabe, mas quanto ignora. Daqui se origina o dito platônico: "Prefiro aprender modestamente as coisas dos outros a ostentar descaradamente as minhas" (HUGO DE SAINT-VICTOR, 2001, p. 157).

Destacamos dois aspectos dessa passagem: o da prudência e do discernimento e o da união de saberes. Em relação ao primeiro, observamos que o mestre vitorino orienta seus estudantes a não desprezar conhecimento e escrito algum, de forma que pudessem ter discernimento e prudência nas ações. Com a humildade e a abertura para o conhecimento, eles se inclinariam para a aprendizagem. $\mathrm{O}$ segundo, interligado ao primeiro, refere-se ao corpus teórico que poderia fundamentar seus estudos: tanto a ciência sagrada quanto a profana deviam compor o ensino e a aprendizagem dos estudantes da Escola da Abadia de Saint-Victor e, por conseguinte, dos homens do século XII, pois faziam parte da história e, porque não dizer, da economia religiosa.

O fato é ainda mais notável na medida em que, mesmo em disciplinas seculares (profanas), existe a historia, como uma das partes da gramática, como título de gênero literário, juntamente com a $<<$ prosa $>>$, os $<<$ metros $>>$, com $<<$ fábulas $>>$ (lib. II, cap. 19). Enunciando estas categorias sem explicar, por razões de brevidade, Hugo retoma de Isidoro (Etim., I, 5, 4) a classificação dos gramáticos antigos, particularmente aquelas fábulas e histórias como artes adequadas, fora da filosofia, da suprema arte, para preparar o espírito (apêndices de artes [...] como são as Tragédias, Comedias, Sátiras [...7, fábulas também e histórias, III, 4; PL 176, 768) para a alta cultura. Voltando à história divina, como ele diz, muda o objeto e o método, apesar da semelhança da forma literária. A historia significa, então, saber o conteúdo desta economia religiosa ao longo do tempo, saber o método original que é imposto a fim de construir como disciplina científica semlhante objeto, oferecido em um texto, de acordo com a letra ${ }^{12}$ (CHENU, 1999, p. 74, tradução nossa, grifos do autor).

Hugo de Saint-Victor não desconhecia as especificidades das ciências (sagrada e profana) e considerava que ambas eram importantes para a formação dos estudantes, das pessoas. De seu ponto de vista, não só tais ciências constituíam a unidade dessa formação, como compunham todo o saber, inclusive o profano. Este era útil à ciência sagrada, ao harmonizar a investigação racional com a vida mística.

Procure em cada ciência somente aquilo que consta pertencer especificamente a ela. Em suma, quando você estiver lendo as ciências e tiver conhecido, mediante discussão e comparação, aquilo que é próprio de uma, aí finalmente será lícito comparar reciprocamente os fundamentos das ciências singulares e, desta consideração comparativa e recíproca, investigar aquelas coisas que anteriormente você tinha entendido menos. Você estará seguro nas discussões quando não tiver medo de errar (HUGO DE SAINT-VICTOR, 2001, p. 145).

\footnotetext{
12 Il fatto è tanto più notevole in quanto, anche nelle discipline profane, l'historia esiste, come una delle parti della grammatica, a titolo di genere letterario, accanto alle $<<$ prose $>>$, ai $<<$ metri $>>$, alle $\mathrm{d}<<$ favole $>>$ (lib. II, cap. 19). Enunciando queste categorie senza spiegarle, per ragioni di brevità, Ugo riprende, attraverso Isidoro (Etym., I, 5, 4), la classificazione dei grammatici antichi, in particolare quelle fabulae et historiae, come artes atte, al di fuori della filosofia, arte suprema, a prepare lo spirito (appendica artium [...] ut sunt tragoediae, comoediae, satirae [...], fabulae quoque et historiae, III, 4; PL 176, 768) all'alta cultura. Passando alla storia divina, come egli dice, cambiano oggeto e metodo, malgrado la somiglianza della forma letteraria. L'historia designa allora sai il contenuto di questa economia religiosa nel tempo sai il metodo originale che s'impone per construire come disciplina scientifica un simile oggeto, offerto in un texto, secondo la lettera (CHENU, 1999, p. 74, grifo do autor).
} 
Em seu entendimento, quanto mais prudência e discernimento o aluno dedicasse ao estudo tanto mais compreensão e reflexão poderia adquirir. Por isso, além da organização e da sistematização nos estudos, o autor apontava a importância do método de aprendizagem. Do contrário, advertia que se encontrariam "[...] muitos estudantes, mas poucos sábios" (HUGO DE SAINT-VICTOR, 2001, p. 139). Isto significa que, diante de um texto a ser lido e das questões nele suscitadas, os estudantes precisariam da memória dos ensinamentos aprendidos aliada à ordenação nos estudos (regras e fundamentos) para definir o que, como e por que ler.

Por modo alegórico, ou alegoria, o autor entendia aquilo que não seria tomado pelo estudante em sentido literal e sim como uma forma de expressão, ou seja, como um modo de interpretação que consiste em representar algo, um pensamento, uma ideia, um sentimento, por vezes subentendido e expresso de modo figurado ou não explícito, mas cuja compreensão poderia ser atingida com prudência e reflexão.

Quero, todavia, que você saiba, estudante, que este estudo exige não sentidos lerdos e idiotas, mas mentes maduras, que devem possuir sutileza na investigação sem perder a prudência no discernimento. Esta é uma comida forte que, se não for mastigada, não pode ser engolida. É necessário, portanto, utilizar-se de um equilíbrio tal, que você, sendo sutil na pesquisa, não seja considerado temerário nas conjecturas [...] (HUGO DE SAINT-VICTOR, 2001, p. 243).

Valendo-se da própria alegoria, ele ensina aos estudantes que ela [a alegoria] seria uma espécie de 'comida forte', densa, que, por isso, requer desenvolvimento intelectivo, prudência, discernimento, 'sutileza na pesquisa'. Assim, eles poderiam entendê-la, livrando-se de posições 'temerárias nas conjecturas', ou seja, desviando-se de condutas precipitadas ou impulsivas, o que prejudicaria o estudo, a pesquisa e a construção de uma base que lhes proporcionasse consistência e unidade na formação.

Neste imenso mar de livros e nestas várias sinuosidades de doutrinas, que amiúde confundem a mente do estudante por número e obscuridade, dificilmente poderá realizar uma construção unitária aquele que não conheceu antes e sumariamente em casa gênero, por assim dizer, algum princípio certo e fundado numa fé firme, ao qual todas as coisas sejam reportadas.

Quer que lhe ensine como devem ser realizadas estas bases? (HUGO DE SAINT-VICTOR, 2001, p. 247).

A última frase da citação revela a atenção e a preocupação do mestre vitorino com a formação de seus estudantes, com o ensino de um caminho que lhes proporcionasse bases sólidas para o estudo. Caso não houvesse regras e ordenação nos estudos, a primeira dúvida encontrada ou um questionamento que lhes fosse feito poderiam desestruturá-los.

Neste contexto, literário e doutrinal, em meio a esta ambiguidade universal da prática alegórica, assume significado e vigor a intervenção de Hugo de São Vítor, que rompe abertamente com um método a seus olhos condenável: contra a alegoria prematura, reage categoricamente a favor da historia e de seu valor insubstituível: fora da letra (carta), tomada como fundamento, se construiria inutilmente. Evitar esse plano e sua técnica fundamental seria como querer ser um gramático sem conhecer o alfabeto. A realidade histórica da Escritura (coisa), e não apenas as palavras (vozes), é significativa: a alegoria é a operação (o processo) eminente pelo qual esta realidade tipológica é transferida para o seu antítipo, porque prenuncia o mistério; mas essa transposição exige, em primeiro lugar, que a realidade histórica seja considerada como um primeiro valor (em sua qualidade/importância primeira). Isto é o que Adam repetiu em Premostratense: $<<$ Pois quanto mais forte, por assim dizer, estará na morada (na casa) o fundamento estabelecido (exposto, suposto) dos nossos livros, tanto mais segura suas paredes erguerão e o telhado sobreposto forte será>> (PL 198, 631 D). Aplicar-se-á, portanto, não apenas para seguir o significado atual do texto, mas para fixar o significado preciso dos termos $<<$ não somente de coisas foi gestada as narrativas, mas daquele principal significado de 
qualquer narrativa, que se expressa de acordo com a propriedade da palavra $>>$, disse Hugo ${ }^{13}$ (CHENU, 1999, p. 225, tradução nossa, grifos do autor).

Chenu (1999), ao tratar do tríplice entendimento das Sagradas Escrituras em Hugo de Saint-Victor, ressalta a pertinência da história e da alegoria, mas ressalva a posição do mestre vitorino em relação à última, apontando que ele era contrário a um entendimento alegórico prematuro. Afirma que, em seus termos, era preciso primeiro ter claro o processo histórico, para então refletir, tecer analogias com o que não estava explícito nos escritos. Aqui, precisamos destacar o cuidado do mestre ao chamar atenção dos estudantes para a alegoria como uma 'comida forte' e também ao atribuir importância à realidade histórica e não apenas às palavras. Ambas [realidade histórica e palavras] eram fundamentais na aprendizagem, na condução dos estudos e nas ações dos homens do século XII.

O modo tropológico, por sua vez, caracterizado pelo sentido figurado, metafórico, devia, na perspectiva vitorina, ser entrelaçado à moralidade, a preceitos e regras que polarizavam, governavam as ações humanas de acordo com a justiça e a equidade natural, isto é, a leis da honestidade e do pudor. Esses aspectos compunham a moralidade nos termos do mestre vitorino, que, assim, entendia que a tropologia "[...] parece mais relacionar-se com o significado das coisas que o significado das palavras", pois "[...] no significado das coisas encontra-se aquela justiça natural, da qual se origina a nossa disciplina moral [...]" (HUGO DE SAINT-VICTOR, 2001, p. 253). O “[...] o significado das palavras se impõe pelo costume, enquanto o significado das coisas foi ditado pela natureza. A palavra é a voz dos homens, a coisa, a voz de Deus aos homens" (HUGO DE SAINT-VICTOR, 2001, p. 209). Ao afirmar que a palavra proferida pelo homem seria uma tênue expressão dos sentidos, ao passo que a coisa seria um simulacro da razão divina, o autor se pautava na tradição cristã do conhecimento, segundo a qual Deus é o criador de todas as coisas.

Nesse sentido, os três modos (histórico, alegórico e tropológico) são pertinentes à formação dos estudantes da Escola da Abadia de Saint-Vitor e, por conseguinte, da civilização cristã no século XII. Eles compunham as bases, os fundamentos do estudo das ciências, sobretudo, o da ciência sagrada. "Na história você tem que admirar os fatos de Deus, na alegoria, crer os seus mistérios, na moralidade, imitar sua perfeição" (HUGO DE SAINT-VICTOR, 2001, p. 241). A perfeição, na tradição cristã, é, justamente, buscar o conhecimento supremo, a sapiência.

Dessa forma, o tríplice entendimento da Sagrada Escritura preconizado por Hugo de SaintVictor é visto como principio educativo e edificante no estudo, pois, ao permitir a compreensão da história, do processo histórico, potencialmente, confere ao estudante uma base teórica sólida para direcionar seus estudos e, com isso, suas escolhas e suas ações na vida.

A edificação seria o princípio norteador do estudante, o sentido no qual ele deve balizar seu estudo. Nessa perspectiva, a Sagrada Escritura cumpriria um papel fundamental, seria a 'pedra angular', aquela que atua como alicerce nas construções antigas, a primeira a ser assentada na aresta do edifício, formando um ângulo reto entre duas paredes. A partir dela se definiria o posicionamento das demais pedras, nivelando e ordenando, assim, toda a construção.

\footnotetext{
${ }^{13}$ In questo contesto, letterario e dottrinale, in mezzo a questa ambiguità universale della pratica allegorica, assume senso e vigore l'intervento di Ugo di San Vittore, che rompe apertamente con un metodo ai suoi occhi condannabile: contro una prematura allegoresi, reagisce categoricamente in favore della historia e del suo valore insostituibile: al di fuori della lettera, assunta come fondamento, si costruirebbe inutilmente. Eludere questo piano e la sua tecnica fondamentale sarebbe come voler essere grammatico senza conoscere l'alfabeto. Le realtà storiche della Scrittura (res), e non soltanto le parole (voces), sono significative: l'allegoria è l'operazione eminente con cui queste realtà tipologiche sono trasferite al loro antítipo, perché ne prefigurino il mistero; ma questa trasposizione impone innanzitutto che la realtà storica sia considerata nel suo valore primo. È quanto ripeteva Adamo il Premonstratense: $<<$ Quanto enim fortius, ut ita loquamur, in domo libri nostri fundamentum suppositum esset, tanto securius eius et parietes erigi et tectum valeret superponi $>>$ (PL 198, 631 D). Ci si applicherà, dunque, non solo a seguire il senso corrente del testo, ma a fissare il significato preciso dei termini, $<<$ non tantum rerum gestarum narrationem, sed illam primam significationem cuiuslibet narrationis, quae secundum proprietatem verborum exprimitur $>>$, aveva detto Ugo (CHENU, 1999, p. 225, grifos do autor).

Educação em Revista|Belo Horizonte|v.36|e223925|2020
} 
Olhe o trabalho do pedreiro: posta a fundação, ele estica a linha horizontalmente, a faz descer perpendicularmente, e em seguida põe as pedras em ordem, polidas diligentemente. E depois procura outras e outras pedras, e, encontrando algumas pedras não conformes às da primeira fila, pega o cinzel, corta as partes excedentes, aplana as partes ásperas e reduz as coisas informes a uma forma, e assim finalmente as acrescenta às outras já dispostas em ordem. E se, por acaso, encontra algumas pedras tais que não possa ser diminuídas nem adaptadas congruentemente, não as usa, para que não lhe aconteça que tentando quebrar a pedra, quebre o cinzel (HUGO DE SAINT-VICTOR, 2001, p. 243-244).

Com essa ilustração do trabalho de pedreiro, o autor propunha que os estudantes não conduzissem seus estudos de modo superficial, mas com atenção, com consistência teórica. Ao elevar seu pensamento, eles não o deixariam vazio ou breve e evitariam que se enfraquecesse com o primeiro questionamento que lhes fosse feito. Semelhantemente ao que ocorre com as pedras que edificam a construção, "A fundação está dentro da terra e nem sempre tem pedras polidas. Mas o edifício está sobre a terra e exige uma estrutura uniforme". Isto nos mostra que o fundamento teórico nos estudos requer profundidade, mesmo que o estudante esteja iniciando seus estudos e, por isso, necessite de uma 'estrutura uniforme', isto é, de disciplina, de lapidar diariamente suas ações de modo a trilhar os caminhos da aprendizagem para chegar ao entendimento, à sabedoria. Esse era o caminho que propunha para que entendessem as Escrituras Sagradas no curso da história, ou seja, um caminho que perpassava pelos modos histórico, alegórico e tropológico: "A fundação sob a terra afigura a história, o edifício que é construído em cima sugere a alegoria. Por esta razão, a própria base deste edifício deve relacionar-se com a alegoria" (HUGO DE SAINT-VICTOR, 2001, p. 245).

Compreendemos, portanto, que, para o mestre vitorino, nem sempre as palavras das Escrituras Sagradas teriam um sentido literal, ou seja, tais escritos poderiam apresentar um sentido ora histórico, ora alegórico, ora tropológico.

Certamente, nem todas as passagens que se encontram no discurso divino devem ser forçadas a ter esta interpretação, como se todo e qualquer texto possa ser imaginado contendo simultaneamente a interpretação histórica, alegórica e tropológica. Bem que muitos textos se prestem a isso, é difícil ou impossível observar o mesmo no texto inteiro (HUGO DE SAINTVICTOR, 2001, p. 205).

Segundo o autor. os livros sagrados não necessariamente deveriam ser lidos e interpretados concomitantemente à luz dos três modos; em sua concepção, esses três caminhos possibilitavam a compreensão da unidade dos escritos sagrados. Desse modo, dentre as palavras divinas que os compõem,

[...] algumas foram colocadas para serem interpretadas só espiritualmente, outras servem para a seriedade moral, algumas foram ditas em sentido simplesmente histórico, outras podem ser expostas convenientemente em sentido histórico, alegórico e tropológico. E assim, de modo admirável, toda a Sagrada Escritura foi adequada e disposta em todas as suas partes pela Sapiência de Deus para que tudo quanto é contido nela faça ecoar, à maneira das cordas, a suavidade do entendimento espiritual. (HUGO DE SAINT-VICTOR, 2001, p. 207, grifo do autor).

Recordamos que, como Hugo de Saint-Victor é considerado um místico (MARCHIONNI, 2001), sua forma de compreender as Escrituras e sua condução educativa estão entrelaçadas a esse entendimento. A experiência mística seria "[...] um entretenimento com a Mente divina" (MARCHIONNI, 2001, p. 14), ou seja, um encontro com a sapiência ao percorrer os ensinamentos propalados pelos mestres e obras estudadas. Essa tradição do conhecimento fez parte da formação de Hugo de Saint-Victor: iniciando-se com o estudo das Sagradas Escrituras e das obras clássicas de sua época, ele se dedicou aos estudos com discernimento, propiciando, assim, o desenvolvimento de seu intelecto. 
Por isso, é necessário tratar as Escrituras Sagradas de modo a não procurarmos em todo o lugar a história, nem em todo o lugar a alegoria, nem em todo lugar a tropologia, mas a situar com competência cada uma delas em seus lugares, como a razão pede. Freqüentemente, todavia, no mesmo texto podem ser encontradas as três juntas, como quando a verdade histórica insinua algo místico através da alegoria, e igualmente demonstra pela tropologia o que deve ser feito (HUGO DE SAINT-VICTOR, 2001, p. 207, grifo do autor).

A compreensão do estudante, fosse ela histórica, alegórica ou tropológica, pressupunha diversos conhecimentos, dentre os quais o das palavras, da leitura e da interpretação que compunha, por assim dizer, as disciplinas das artes liberais, das ciências profanas e sagradas. Com base em tais conhecimentos, ele poderia se aproximar da sapiência.

Tal sistematização do saber é considerada uma inovação da exegese dos vitorinos, o que pode ser evidenciado nas palavras de Chenu (1999, p. 227-228, tradução nossa, grifos do autor):

Esse caráter inovador da exegese de São Vitor é agora bem compreendido e conhecido. Mas gostaríamos de insistir na construção da teologia que Hugo e seus discípulos propõem a partir deste método histórico. O Didascalicon não é somente um modo de leitura (VI, 1; PL 176, 799 A) que chama as leis da exegese da Escritura de acordo com as categorias tradicionais, história, alegoria, tropologia, anagogia, propõe uma metodologia da ciência, da ciência sagrada como da ciência seculares, portanto, uma teologia organizada, edificada, construída. A imagem que constantemente vem das penas dos Vitorinos não é mais a evocação dos três afluentes que, na primeira era do mundo, de acordo com o mito primitivo, fecundava o solo e repartia a riqueza, mas a imagem de uma construção arquitetônica, a fábrica (fazer) espiritual (VI, 4; PL 176, 802805), dos quais precisamente a controvérsia (disputa) do tabernáculo reforçava a representação. A Escritura não é somente uma sucessão de histórias curtas, de proposições, de ensinamentos; ela tem uma estrutura que deve, para ser lida sabiamente, aparecer em sua construção $0^{14}$ $<<$ Porque ela também [Escritura] possui uma estrutura $>>$ (Cf. VI, 4; PL 176, 802 B).

Denominando o tríplice entendimento das Sagradas Escrituras em Hugo de Saint-Victor como 'três afluentes', o autor ressalta o caráter inovador da Escola da Abadia de Saint-Victor em relação à exegese e denota que essa concepção se caracterizou como uma construção histórica. Essa construção é importante por dois motivos. Primeiro, porque se refere à concepção de Trindade; segundo, porque possibilita a compreensão dos escritos, não só sagrados, mas também seculares, justamente porque estes têm uma estrutura, uma organização. Deles podem-se extrair ensinamentos que possibilitam a edificação a quem os procura: aquela edificação explicitada alegoricamente por Hugo de Saint-Victor. Em suma, trata-se de uma ordenação nos estudos com base em dois aspectos essenciais: um caminho teórico mapeado pela Trindade, que, sendo trino, simboliza a perfeição do conhecimento (Deus é Pai, Filho e Espírito Santo); outro, que põe em prática os ensinamentos aprendidos, de lapidar as ações humanas.

Que todas as coisas estão nessas três

\footnotetext{
14 Questo carattere innovativo dell'esegesi di San Vittore è ormai ben chiaro e conosciuto. Ma vorremmo insistere sulla costruzione della teologia che Ugo I suoi discepoli propongono a partire da questo metodo storico. Il Didascalicon non è solamente un iter legendi (VI, 1; PL 176, 799 A) che richama le leggi dell'esegesi della Scrittura secondo le tradizionali categorie, historia, allegoriae, tropologia, anagogia, propone una metodologia delle scienze, della scienza sacra come delle scienze profane, dunque di una teologia organizzata, edificata, costruita. L'immagine che costantemente si presenta sotto la penna dei Vittorini non è più l'evocazione dei ter fiumi che, nella prima età del mondo, secondo il mito primitivo, fecondavano il suolo e ne ripartivano le ricchezze, ma l'immagine di una costruzione architettonica, fabrica spiritualis (VI, 4; PL 176, 802805), di cui appunto la controversia del tabernacolo rafforzava la rappresentazione. La Scrittura non è solamente una succesione di racconti, di proposizioni, d'insegnamenti; ha una strutura, che deve, per essere letta intelligentemente, apparire nella sua costruzione. $<<$ Nam et ipsa [Scriptura] structuram habet $>>$ (Cf. VI, 4; PL 176, 802 B) (CHENU, 1999, p. $227-$ 228, grifos do autor).
} 
Quaisquer que sejam as coisas ditas de Deus, e verdadeiramente acreditadas em Deus, são referidas a essas três [as três pessoas da trindade] e elas consistem Nele; destas, como já foi dito, se você tira alguma coisa, o que resta não é perfeito; e se você tentar adicionar alguma coisa, o que é amplificado não é maior. Pois se você o chama de forte e incorrupto, imutável e invencível, e outros termos semelhantes, tudo isso aqui é do Seu poder; se você o chamar de providente, de inspetor, de escrutinador de segredos, e de inteligente, tudo isso é da Sua sapiência; se você o chamar de piedoso, se for bondoso, se for misericordioso, se for paciente, tudo isso é da Sua bondade. E na verdade não se pode acrescentar nada a estas coisas, porque tudo está contido nelas, o que é perfeito e verdadeiro: portanto, esses três designam a Trindade em perfeita semelhança; e convencem de que nada deve ser acrescentado aos três, porque é perfeito, e nada deve ser tirado, pois assim está completo: esses três em Deus era um só, e para Deus eles eram um, mas foram encontrados distintos aqui onde eram próprio, e portanto eles se tornaram uma imagem da Trindade. A consideração seguiu a propriedade encontrada aqui até mesmo a inefável Trindade, e distinguiu como peculiar ali o que era peculiar apenas aqui, e algo diferente foi encontrado: três, de fato, em um era tudo, e tudo era um ${ }^{15}$ (HUGONIS DE S. VICTORE, 1880 , p. 232, tradução nossa).

No caminho teórico da Trindade está implícita a sistematização do saber proposta aos estudantes. Nele, o autor preza a busca da totalidade do conhecimento. Em diversos momentos das obras analisadas, ele destaca, com sua didática, a forma trina como método para a realização satisfatória do saber almejado: 'tudo, de fato, em um era tudo e tudo era um'.

Nesse sentido, por exemplo, na obra Didascalicon, o mestre trata, dentre outras questões, do tríplice entendimento da Sagrada Escritura, ou seja, o modo histórico, alegórico e tropológico; das três coisas necessárias aos estudantes: 1) as qualidades naturais, 2) o exercício e 3) a disciplina; e da tríplice potência da alma (vegetativa, sensitiva e racional).

Na obra De sacramentis, por sua vez, o mestre vitorino trata de três elementos qualitativos do homem: a sabedoria, a prudência e a sensualidade/sensibilidade. Em relação ao sacramento, para discerni-lo, o autor se refere a três aspectos: a semelhança natural, a instituição e a santificação. A administração eclesiástica, segundo Hugo de Saint-Victor, consiste em três aspectos: as ordens, os sacramentos e os preceitos. Já, no que diz respeito à restauração humana, os três aspectos seriam: o tempo, o lugar e o espaço. Assim, compreendemos que o caminho teórico vitorino contempla o trino estudo. O número três, então, é entendido como a perfeição do conhecimento.

Compreender e ordenar o estudo de forma trina, seja considerando as qualidades naturais, o exercício e a disciplina do estudante, seja analisando a Sagrada Escritura pelo modo histórico, tropológico e alegórico, conduz o estudante (o jovem teólogo) a um itinerário formativo. É o que expressam os ensinamentos contidos tanto no Didascalicon quanto em De sacramentis.

Para dirigir eficazmente o jovem teólogo nesta $<<$ fabrica espiritual $>>$, Hugo empreende sua suma De sacramentis, compêndio de doutrina que servirá como uma introdução a este segundo ensinamento, segunda erudição (aprendizagem) que é uma alegoria. O De sacramentis assim se insere entre um primeiro aprendizado, que consiste na lição de história, e um segundo fundada na alegoria. $<<$ Ao ensinar com base no texto relacionado a ordem da história, a sucessão da história com suas contingências (contexto) e seus obstáculos, o estudo alegórico, libertado dessa servidão e assegurado por uma firme didática dos mistérios (De sacramentis), torna possível a ordem

\footnotetext{
15 Et quæqunque de Deo dicuntur, et creduntur veraciter in Deo: ad hæc tria referuntur et constat in his tribus in ipso, quibus, ut dictum est, si qui tollas perfectum non est quod relinquitur; si quid adjicere coneris, majus non est quod explicatur. Si enim fortem dicis et incorruptum et incommutabilem et invicibilem et cætera quæ similia sunt, hic totum hoc potentiæ est; si providum, si inspectorem, si scrutatem oculta, et intelligentem, hoc totum sapientiæ est; si pium, si mansuentum; si misericordem, si patientem, totum hoc bonitatis est. Et non potest his adjicere veritas quidquam, quia totum in his continetur quod perfectum est et verum: ideo tria hæc veritatem monstraverunt in simulacro perfecto et persuaserunt nihil adjiciendum tribus, quia hoc perfectum est, et nihil tollendum quoniam sic constat consummatum: et tria hæc in Deo erant unum; et Deo unum erant, sed distincta inventa sunt hic ubi non erant unum; et proptera Trinitatis imago facta sunt. Et secuta est consideratio proprietatem inventam hic usque ad ineffabilem Trinitatem; et distinxit ibi propium quod proprium hic erat tentum, et differens inventum est; ibi autem in uno erat totumet unum totum (HUGONIS DE S. VICTORE, De sacramentis... L. I, p. III, c. 29, tradução nossa).
} 
doutrinária $>>$. A Suma é assim colocada, portanto, pedagogicamente e metodologicamente, entre o estudo histórico da Bíblia e seu estudo alegórico, a suprema construção do teólogo. A teologia não só nasce a partir da Escritura, mas na Escritura se compõe ${ }^{16}$ (CHENU, 1999, p. 228-229, grifo do autor, tradução nossa, grifos do autor).

De acordo com Chenu (1999), as obras vitorinas - Didascalicon e De sacramentis - podem ser consideradas um compêndio de doutrina (no sentido latino, cultura, instrução, educação), cujos ensinamentos pressupõem o conhecimento do processo histórico, a ordenação nos estudos (método), a didática, contemplando, assim, a sistematização do saber considerada necessária à construção do estudante (teólogo).

\section{CONSIDERAÇÕES FINAIS}

A proposta de formação e de restauração do homem em Hugo de Saint-Victor obedece a uma perspectiva cristã que abrange o homem citadino e sua forma de se apropriar do presente. Com base em uma tradição de conhecimento, o autor propõe caminhos para esse homem, os quais são permeados pela memória, pela história e pela sistematização do saber. Em sua proposta, para ensinar, é preciso recuperar no ser humano sua característica fundamental, que é o pensar reflexivo.

Observando que, para ele, a compreensão do processo histórico é a base teórica de sustentação da aprendizagem e que apropriação do conhecimento ocorre pela memória, já que sem memória não há história, entendemos sua ideia de que o estudo permite o desenvolvimento intelectivo (o engenho). É necessário, portanto, desenvolvê-lo, aprimorar e abstrair o conhecimento por meio da memória para adquirir a sabedoria. A memória, nesse sentido, é compreendida como uma das funções da alma, o fundamento do conhecimento.

O mestre, por sua vez, seria o responsável pelo desenvolvimento de outro sujeito, deveria se empenhar em ser sábio e restaurado. Contudo, tanto a sabedoria do mestre quanto a do estudante se desenvolviam na esfera inteligível, formada pela esfera intelectível divina. Eram sabedorias da vida inferior (inteligível); já, a do Criador, era a sabedoria superior (intelectível). Isso significa que, no homem, ela se expressava como forma (possibilidade de desenvolvimento) e, em Deus, como sua natureza, que é trina. Cristo, portanto, como segunda pessoa da Trindade que confere à humanidade a sapiência do Criador, seria o espelho necessário ao ofício de mestre, porque é o modelo de perfeição e sabedoria da vida, a união do conhecimento com a ação prática. Com efeito, o fato de ser mestre não fazia dele, necessariamente, um ser sábio e restaurado. Consagrar-se mestre implicava, além de um compromisso pedagógico, firmar um compromisso ético, intelectivo e político com a cristandade. No caso do mestre vitorino, esse compromisso era com a comunidade da Abadia e da Escola de SaintVictor.

Para o autor, a sapiência era essencial para a mística, era um caminho teórico, pois possibilitava que a pessoa se utilizasse da contemplação meditativa para encontrar o vigor e o conhecimento necessários à condução da vida, espiritual e social (o pensar e o agir humanos). Em sua compreensão mística, a totalidade do ser humano seria composta de corpo e alma, seria espiritual e social. Espiritual, porque nela se encontra a alma (princípio animador do corpo) e o desenvolvimento do intelecto. Social, porque se considerava o presente, o século XII, o contexto da Reforma Gregoriana e do renascimento a ela inerente. Ensinar, para o mestre vitorino, pressupunha responsabilidade, compromisso com a ação social, não podendo ser realizada por alguém alheio ao mundo espiritual.

\footnotetext{
16 Per dirigere efficacemente il giovane teologo in questa $<<$ fabrica spiritualis $>>$, Ugo intraprende la sua somma $D e$ sacramentis, compendio di dottrina che servirà da introduzione a questo secondo insegnamento, secunda eruditio quae in allegoria est. Il De sacramentis s'inserisce dunque tra una prima eruditio, che consiste in historia lectione, e una secunda fondata sull'allegoria. $<<$ Mentre l'insegnamento basato sul testo è legato all'ordine del racconto, alla successione della storia con le sue contingenze e i suoi impedimenta, lo studio allegorico, affrancato da questa servitù e garantito da una ferma didattica dei misteri (De sacramentis), rende possibile l'ordine dottrinale $>>$. Le Summae si collocano dunque cosi, pedagogicamente e metodologicamente, tra lo studio storico dela Bibbia e il suo studio allegorico, suprema costruzione del teologo. La teologia non soltanto nasce dalla Scrittura, ma nella Scrittura si compie ${ }^{16}$ (CHENU, 1999, p. 228-229, grifo do autor).

Educação em Revista|Belo Horizonte|v.36|e223925|2020
} 
Dessa forma, ele pregava a prática das virtudes, o esmero, o refinamento interior, a dedicação, própria de quem preservava o conhecimento intelectivo e o desenvolvia em consonância com a sensibilidade afetiva, evidenciando esforço e diligência. Por esse caminho, o homem encontraria a restauração, ou seja, por meio dessa totalidade de saberes o homem se restauraria e, assim, chegaria ao objetivo final do estudo: a sapiência (sabedoria).

Enfim, concluímos que uma das contribuições que a Idade Média legou ao ensino foi a necessidade de saber de memória o que se aprende. Memorizar, recordar, é 'saber de cor', é saber com o coração, pois, para o mestre vitorino, amar o conhecimento significa assimilar primeiro com o coração e depois com a mente.

\section{REFERÊNCIAS}

CHENU, Marie-Dominique. La teologia nel XII secolo. Introduzione di Inos Biffi. Traduzione Paolo Vian. Milano: Editoriale Jaca book SpA, 1999.

COELHO, Maria Filomena. Prefácio. In: RUST, Leandro Duarte. A reforma papal (1050-1150): trajetórias e críticas de uma história. Cuiabá: AdUFMT, 2013.

GRYZBOWSKI, Lukas Gabriel. Política: entre a teoria e a práxis no século XII. O De sacramentis de Hugo de S. Victor e a Historia de duabus civitatibus de Otto de Freising. Roda da Fortuna. Revista Eletrônica sobre Antiguidade e Medievo, v. 3, n. 2, p. 124-147, 2014.

HUGO DE SAINT-VICTOR. Didascálion: Da arte de ler. Petrópolis: Vozes, 2001.

HUGONIS DE S. VICTORE. De sacramentis fidei christianae. In: MIGNE, Jacques-Paul. Patrologia

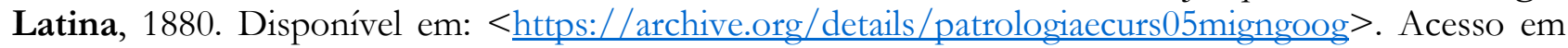
07 maio 2019.

LE GOFF, Jacques. As raízes medievais da Europa. Petrópolis: Vozes, 2007.

MARCHIONNI, Antonio. Introdução. In: HUGO DE SAINT-VICTOR. Didascálion: Da arte de ler. Petrópolis: Vozes, 2001.

POIREL, Dominique. Ugo di San Vittore: storia, scienza, contemplazione. Millano: Jaca Book, 1997. Disponível $\quad$ em: $<$ https://books.google.com.br/books?id=vofPui9v71AC\&pg=PA143\&lpg=PA143\&dq=D.+Van+Den + Eyden+-

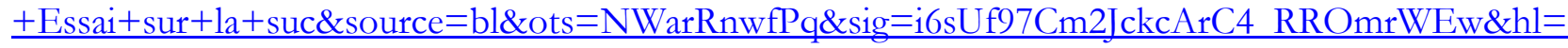
$\mathrm{pt}-$

BR\&sa $=X \& v e d=0$ ahUKEwjL5rv01uDVAhWEl5AKHXb B5YQ6AEIKTAA $\#_{\mathrm{v}}={ }_{\text {onepage } \& \mathrm{q}=\mathrm{de} \% 2}$ 0sacramentis\&f=false $>$. Acesso em: 08 maio 2019.

SICARD, Patrice. Hugues de Saint-Victor et son école. Brepols, 1991.

VERGER, Jacques. Cultura, ensino e sociedade no Ocidente nos séculos XII e XIII. Bauru, SP: EDUSC, 2001. 